\title{
LA PROMISCUIDAD DEL SIGNIFICADO: NÉSTOR PERLONGHER
}

\author{
POR \\ JILL KUHNHEIM \\ University of Wisconsin-Madison
}

Barbara Johnson empieza su lectura prodigiosa de un poema de Mallarmé en su libro, The Critical Difference [La diferencia crítica], con una meditación más generalizada acerca del entretejemiento de los placeres literarios y sexuales:

\begin{abstract}
Somehow [she says], it is not simply a question of literature's ability to say or not say the truth of sexuality. For from the moment literature begins to try to set things straight on that score, literature itself becomes inextricable from the sexuality it seeks to comprehend [...]. Literature is not only a thwarted investigator but also an incorrigible perpetrator of the problem of sexuality (13).

[De alguna manera (dice ella), no es sencillamente una cuestión de la capacidad de la literatura para decir o no decir la verdad de la sexualidad. Porque desde el momento en que la literatura empieza a intentar poner algo en su justo sitio, la literatura misma se implica en la sexualidad que busca comprender [...] La literatura no es solamente un investigador frustrado sino también un responsable obstinado del problema de la sexualidad. $]^{1}$
\end{abstract}

Elijo citar la caracterización que hace Johnson de un lazo muy comentado entre la literatura y el deseo para abrir mi examen de la poesía de Néstor Perlongher tanto por el tema como por la terminología que emplea aquí. La literatura es un "investigador frustrado", un "responsable obstinado" - este lenguaje legalista vincula la sexualidad a lo ilícito y convierte lo literario en cómplice de un "crimen" sexual. La escritura, por lo tanto, es accesoria y adorno de la pasión, y parece que la literatura no puede "set things straight" (poner algo en su justo sitio).

Aunque la exégesis específica de Johnson trata del uso sutil y seductivo de la indeterminación para revelar la fascinación entre un "explorador" masculino y una francesa sin nombre, esta última frase (me refiero a "set things straight") leída en los Estados Unidos en 1998 , anima un subtexto gay que es difícil pasar por alto. ${ }^{2}$ Su declaración, de hecho, nos

\footnotetext{
1 Todas las traducciones incluidas aquí son mías, si no se indica lo contrario.

2 "Gay" es un término ya adoptado en muchos países hispanoamericanos. Mientras el significado exacto de la palabra cambia según su empleo en lugares distintos, en general se lo ha adaptado en contra de términos tradicionales más estigmatizados (una exploración interesante de sus usos es el artículo "Stigma Transformation and Relexification: Gay in Latin America" por Stephen O. Murray y Manuel Arboleda G.).
} 
ofrece un anuncio misterioso de algunas ideas recientes asociadas con la producción literaria de identidades homosexuales. Por ejemplo, Lee Edelman, en Homographesis, propone que en las culturas occidentales,

Like writing, gay male sexuality comes to occupy the place of the material prop, the excessive element, of representation: the superfluous and arbitrary thing that must be ignored, repressed, or violently disavowed in order to represent representation itself as natural and unmediated" (xvi). [Como la escritura, la sexualidad del hombre gay llega a ocupar el lugar de sostén material, elemento excesivo, de la representación: la cosa superflua y arbitraria que se debe ignorar, reprimir, o negar violentamente para representar la representación misma como si fuera natural y no mediada].

Edelman propone que la sexualidad se constituye por operaciones tanto retóricas como psicológicas y que la homosexualidad masculina constituye la frontera de la representación, ofreciendo un espacio posible de resistencia a los términos dualistas de la sexualidad y la retórica dominantes (xiv). Llevar el subtexto gay a la superficie, entonces, aumenta los papeles posibles de la literatura tanto para reforzar como para desviarse del camino recto de la sexualidad.

La poesía de Néstor Perlongher nos provee un ejemplo seductor de este instigar y vigilar de la pasión, de este juego entre el texto y el subtexto en otro contexto. Perlongher, nacido en las afueras de Buenos Aires en 1949, fue un poeta y profesor de antropología social que pasó la mayoría de su vida profesional en el Brasil, donde murió en 1992. Publicó seis poemarios en su vida, más un estudio acerca de la prostitución masculina en São Paulo, y un libro sobre el SIDA, traducido al castellano como El fantasma del SIDA. ${ }^{3}$ Mientras la muerte no es un tema constante en su obra, su poema más conocido es, tal vez, "Cadáveres" (Alambres), un poema que fantasmagóricamente textualiza la ausencia entre una serie de referencias nacionales. ${ }^{4}$ Sombreado por cuerpos y por el SIDA, la obra de Perlongher también es frecuentada por Evita. Una presencia multivalente en su escritura, ella incorpora la muerte en vida, un zombi, una mujer construida que personifica la teatralidad y la presencia material de la muerte, al mismo tiempo que también es figura nacional y un ícono gay. Su imagen en esta poesía a la vez obscurece y proporciona un atajo a una ausencia; ella paradójicamente estorba o desvía la atención del deseo homosexual, a la vez que lo ilumina continuamente.

La función de Evita cambia en la obra de Perlongher. Podemos observar este cambio si empezamos con una de sus apariciones tempranas, en el poema "El cadáver" de AustriaHungría y la contrastamos con su aparición después en el cuento, "Evita vive", la reseña, "Joyas macabras", y el poema, "El cadáver de la nación" (Hule). El cambio en la representación de Evita entre estos textos, y particularmente entre los dos poemas que, por

\footnotetext{
${ }^{3}$ Esta es la lista completa de las publicaciones de Perlongher: Austria-Hungria (1980); Alambres (1987); Hule (1989); Parque Lezama (1990); Aguas Aéreas (1991); El chorreo de las iluminaciones (1992); Lamê: Antología bilingüe espanhol- português, 1994). Sus artículos están recogidos en Prosa plebeya (1997).

4 Algunos de estos poemas evocan la literatura y la historia argentina; unos títulos ejemplares de Alambres son: "Rivera" y "Para Camila O'Gorman", y poemas que incluyen epígrafes de Esteban Echeverría y de la Historia de la confederación argentina de Saldías.
} 
las fechas de su publicación, marcan el comienzo y fin de su tratamiento del tema, señala una transformación más amplia en el estilo del autor, hacia el neo-barroco, y un cambio en cómo se textualiza la identidad gay en su obra. Evita delinea el traslado de un subtexto gay a una textualidad gay. En el poema más tardío, la identidad homosexual es una puesta en escena patente, una mise en scène barroca que enfatiza la construcción de identidades múltiples: sexuales, nacionales, y transnacionales.

En el poema más temprano que se centra en Evita, "El cadáver", hay una trama elemental, aunque misteriosa; el hablante poético recuerda "esa noche", la cual, descubrimos, es la noche cuando murió Evita (se señala eso, en parte, por la referencia temporal: 20.25 de la noche). También es una referencia personal porque ésta también es la noche en la que el hablante no entró en el pasillo:

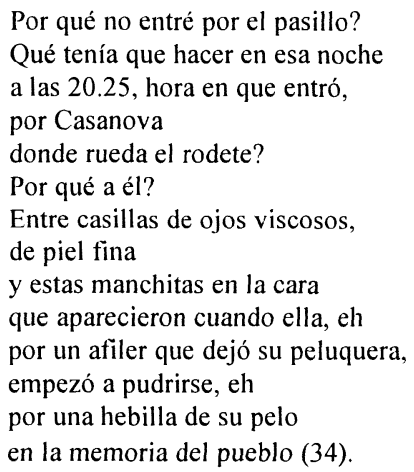

La memoria de su dubitación es la acción inicial del poema y deslinda un momento de transición que une los tres actores distintos: el yo poético que vacila; ella, Evita, en transición de la vida a la muerte, de persona a cuerpo en este momento recordado; y él, alguien en el pasillo cuya presencia cambia una y otra vez.

"Él" podría estar sólo o con un grupo ("entre cervatillos de ojos pringosos, / y anhelantes / [...] torvos / dulces en su melosidad de peronistas") y su presencia es tanto atractiva ("piel fina") como amenazante ("por temor a un olvido / intranscendente, a un hurto"). ${ }^{5}$ "Él", como el momento descrito, también está frecuentamente yuxtapuesto o confundido con Evita:

Por él,

por sus agitados ademanes

${ }^{5}$ La edición del texto que empleo es bilingüe - se incluyen los poemas en español y portugués en las páginas opuestas. La traducción del portugués (por Josely Vianna Baptista) provee algunas percepciones interesantes en relación a los poemas originales. Por ejemplo, se traduce el término "cervatillos" como "veadinhos" - una palabra muy común en la jerga para referirse a los hombres homosexuales en el Brasil. No puedo confirmar esta misma connotación en la jerga argentina y, puesto que se publicó esta colección después de la muerte de Perlongher, sólo podemos especular acerca de su posible convalidación de esta traducción. 
de miseria

entre su cuerpo y el cuerpo yacente

de Eva, hurtado luego,

depositado en Punta del Este

o en Italia (36).

El fin del verso momentáneamente pospone la posibilidad de identificar de quién es este cuerpo postrado, así como la selección de palabras - "hurtado" prefigurando el "temor a un hurto" que luego aparece - constantamente obscurece la identidad en el poema.

Esta repetición y confusión de personajes le da al poema una calidad de ensueño; todos sus elementos parecen ser fragmentos de un todo. Sin embargo, cómo se funden el uno y el otro es significativo. En la cuarta estrofa el hablante parece cambiar, dirigiéndose a un "tú" en un tono coloquial; éste podría ser la voz de "él" dirigiéndose al yo poético, o podría ser otro lado del mismo hablante, porque sufre del mismo dilema: no poder entrar. También podría ser la voz del lector de este poema, regañándole al autor por jugar con la muerte de Evita e impedir nuestra entrada al texto. En la sexta estrofa el yo poético cambia otra vez, esta vez a un "nosotras" que rehusa entrar (¿en qué? ¿el pasillo? ¿la inmortalidad?), aunque sigue el cortejo funerario. Esta fusión evoca la negación y hesitación colectiva del momento histórico, pero sin eclipsar la historia individual aquí. ${ }^{6}$

La transición de Eva de hecho se hace en un momento de juicio para el hablante. Encontramos que su vacilación es producida por su miedo: miedo a las clases populares, miedo de un hurto - figurado por el muchacho/los muchachos y el peronismo- miedo a la muerte. Y por su deseo: por lo físico, por la oportunidad, por el sexo ("la petite mort"), representado por el muchacho y por la posibilidad de entrar. Como ya observamos la imagen de "él", el poema incluye muchas alusiones a posibilidades homosexuales: "Si él no me hubiera dicho entonces que está sólo, / que un amigo le plancha las camisas / y que precisaría, vamos, una ayuda" (40). Pero la "deseada sordidez" se contiene por "ese deseo de no morir," Eros se enlaza con Thanatos, de la misma manera que el muchacho se enlaza con Evita, cuya entrada al otro mundo se pospone por la añoranza de la gente. Le deja al hablante titubeante, "como en un juego" (42).

En una entrevista, Perlongher describe la presencia de Evita en el poema como un "atajo":

un anclaje, para que la perturben, con más tranquila insidia, las cataratas de otros incidentes - en el ejemplo de este poema, unos chongos de una villa de miseria que me invitan a una casilla donde no me animo a entrar. ${ }^{7}$ Evita es, en este sentido, un atajo: tanto un poema "político" (o micropolítico) sobre el atajo —que consistía en la Argentina del 70 en

\footnotetext{
"El empleo de lo femenino aquí llama la atención; en vez del esperado "nosotros", masculino y universal, "nosotras" es particular. A primera vista, parece referirse a las "muchachas comunistas" que aparecen después, pero el hablante dice que ellas hubieran entrado. Otra posibilidad es que el uso de lo femenino es una referencia cifrada a la identidad gay.

7 Antes, en la misma entrevista, hablando de la desterritorialización del lenguaje, Perlongher define el término "chongo" en relación a la novela Maitreya de Sarduy como un "chulo o bujarra del argot rioplatense", haciendo explicita la referencia gay.
} 
encaramarse al peronismo para hacer la revolución - como un atajo literario, un cortar camino para la reverberación de ciertas sensaciones poéticas (287).

Evita funde la política y la poética con un tercer término, el elemento no mencionado - lo erótico. Lo que llama la atención además es el orden de estos elementos. El deseo aquí es por él, y Evita - su muerte, la historia, la política - desaloja metonímicamente este deseo homosexual. "Atajo", por lo tanto, es una sugerente elección de palabras para describir este proceso porque un atajo es un camino más directo (como fue la imagen de Evita para la izquierda argentina, según el autor) y también una escisión, un corte. ${ }^{8}$ El sentido menos común de la palabra describe cómo Evita funciona para dislocar lo homoerótico; al mantenerlo al nivel fantasmagórico, se alude a ello, pero puede pasar desapercibido. Perlongher inscribe la pasión en este poema, pero lo hace en el lenguaje codificado de un grupo reprimido dentro de la cultura dominante." Emplea un lenguaje cifrado que lo deja hablar dentro y fuera del grupo a la vez, alternando entre revelar una identidad homosexual y divulgar lo que se podría leer como una ceguera "histérica".

Lo que observamos en el caso de "El cadáver" se puede extender al poemario entero. Hay una vacilación continua entre demostrar una identidad homosexual y ofuscarla. Poemas como "Los orientales," que trata de la prostitución masculina, "El polvo," que mantiene un diálogo entre un chongo y un marica mientras entreteje los pronombres él y ella, "Por qué seremos tan hermosas" y "Anales", en los cuales hay referencias bastante claras al sexo "perverso" y a la sodomía, aparecen entre poemas con temas distintos, muchas veces internacionales, como indica el título de la colección, Austria-Hungria ("Crimea," "La murga, los polacos"). Lo que une esta amalgama de poemas es la ubicación del hablante poético que se sitúa discursivamente a la vez dentro del grupo (nacional o sexual) y en sus márgenes. Demuestra una y otra vez la naturaleza fluida y cambiante de cualquier identidad construida en el lenguaje.

Lo que atrae al poeta en la figura tan céntrica de Evita es, irónicamente, precisamente su marginalidad. En su comentario sobre el libro Evita. A militante no camarim, escrito por Horacio González y publicado en 1983 en portugués, Perlongher explica el discurso sentimental que circundaba a Evita como "irresistible" porque:

tanto la gritería antioligárquica (altisonante y vacua) como cierto amoralismo que destilaba del noviazgo entre el militar (acusado de estuprar a una estudiante de secundaria) y la actriz (apodada "mujer fácil") eran un desafío a los ojos de la pacata aristocracia local, en medio del perfume hedonista de la orgía distributiva del Justicialismo (Prosa 201).

\footnotetext{
${ }^{8}$ Las dos últimas definiciones del Diccionario de la Real Academia Española son: "3. Separación o división de alguna cosa 4. Acción y efecto de atajar un escrito".

"Bruce Boone elabora esta idea en relación a la poesía del norteamericano, Frank O'Hara, proponiendo que "the critical repression of this antagonistic sexual question [in O'Hara's work] is in fact a repression of a politically oppositional language" (63) [la represión crítica de esta cuestión sexual antagónica (en la obra de O’Hara) es de hecho una represión de un lenguaje político oposicional]. La teoría de Boone nos ofrece una construcción más amplia de lo político, dejándonos ver el erotismo restringido en la obra temprana de Perlongher como una práctica social excluida tanto por el Peronismo como por la Izquierda.
} 
Ubica la manipulación de su imagen por González como una entre muchas que combinan el deseo, la política, y el poder, y él emplea otra vez en este artículo la palabra "atajo" para describir el intento de los revolucionarios de apoderarse del signo de Evita. Ésta se revela como una estrategia de doble filo porque Perlongher termina su reseña afirmando que siempre, "en el fondo de este corredor hay un cadáver (¿que se maquilla?)" (Prosa 202). Evita ofrece múltiples posibilidades de significación, de pintura, y el concepto de maquillaje no es casual sino que exhibe varios sentidos en la obra perlongheriana. Además de evocar la significación, la escritura en una superficie, señala la sobrecodificación del "maquillado virilismo" cuando se examina la prostitución homosexual (Prosa 39). Luego el verbo aparece en su sentido de cubrir, tapar: "Esta guerra [social en contra de los márgenes] que no cesa se puede maquillar de política"; la política es el discurso cosmético que reviste la violencia de "gestos paternalistas" (Prosa 41). ${ }^{10}$ Se recodifica a Evita aquí para señalar el desvío del sentido; su cuerpo es el espacio del juego imaginario que, a veces, alcanza intersecciones significativas con la realidad.

La desterritorialización, el nomadismo del cadáver tiene ciertos paralelos con la vida del poeta, que rearticula lo nacional por la imagen de Evita desde una distancia. Varios críticos han asociado este tipo de exilio con su interés por Deleuze y el nomadismo del deseo en la prostitución homosexual (ver, por ejemplo, Panesi 58). Y casi siempre hay un desliz desde el vagar hacia lo sexual en la Evita de Perlongher porque, como bien lo explica Christian Ferrer, él la considera una destilación del deseo en sí: "Néstor reconoció en la idolatría política de la masa peronista hacia Evita al deseo en estado químicamente puro: las vibraciones morales pasan entonces a segundo plano" (187). Un paso más le lleva a entretejer este deseo "puro" con la profanación." "Evita vive", un cuento tildado por varios como "blasfemo y maldito" (González 10), nos ofrece un ejemplo de este deseo de profanar mucho más fuerte del que encontramos en la poesía. Pero, a la vez, encontraremos que el poder y la santidad de la imagen de Evita son también irónicamente reforzados por su deseo de profanarla.

La historia de la publicación de este cuento es una peregrinación en sí: aunque se dice que fue escrito en 1975, fue publicado por primera vez en 1983, en inglés, en una colección gay estadounidense; en 1985 apareció en Suecia; luego, en una publicación marginal en Buenos Aires en 1987 (Cerdos y peces, revista dirigida por El porteño), para finalmente publicarse en El porteño de 1989, donde recibió una circulación más amplia y una reacción argentina más aguda. ${ }^{12}$ Este cuento, que se puede imaginar cambia de sentido radicalmente

10 El concepto del maquillaje como un tipo de escritura en el cuerpo otra vez nos recuerda el "homographesis" de Edelman que se define, brevemente, como este proceso "whereby homosexuality becomes a subject of discourse, and therefore a subject on which one may write, coincides with the process whereby the homosexual as subject is conceived of as being even more than as inhabiting, a body on which his sexuality is written" ("Tearooms" 571) [por el cual la homosexualidad se hace un sujeto del discurso y, por lo tanto, un sujeto en el que se puede escribir, coincide con el proceso por el cual se concibe del homosexual como un sujeto, siendo más que ocupando, un cuerpo en el cual se inscribe su sexualidad].

$"$ En su prosa se observan las referencias directas a varios autores que tratan el tema de lo profano, lo excesivo, como Bataille, Sade, Genet, Deleuze y Guattari.

12 Ver la nota extensa de Christian Ferrer y Osvaldo Baigorria para los datos completos y un comentario sobre la historia de su publicación (Prosa 191). 
según la ubicación nacional de sus lectores, tenía que llegar a la médula — su audiencia argentina - por un camino no recto sino torcido.

"Evita vive" se compone de tres partes numeradas que se entretejen, se reflejan, y que nos proveen una visión prismática de una Evita totalmente corrompida. No son cuentos distintos sino partes enlazadas por esta imagen central y por una serie de escenarios y actividades unidos por su marginalidad - un hotel de bajo fondo, un coche, una casa, donde se combinan las drogas y lo sexual. En cada episodio hay un juego entre lo masculinofemenino, la "realidad" y la "apariencia", creando un tipo de travestismo, porque el narrador presenta a su Evita como la Evita, evidentemente resucitada y llevando una vida extraordinaria en un mundo de maricas. Como siempre en la obra de Perlongher, ella es identificada por ciertas partes de su cuerpo - su pelo, por ser rubia, el rodete, las uñas. Se la condensa en una sinécdoque, partes de ella la producen como imagen, y su totalidad se desplaza en un movimiento metonímico. Este desplazamiento es significativo porque no sólo produce a Evita aquí, sino también un ser femenino; la identidad femenina se muestra como rastros de un disfraz. Al evocarla por sus partes, la imagen de Evita se deshace mientras se hace; finalmente la imagen queda pulverizada, se hace polvo.

En un ensayo sobre la poesía de Perlongher, Delfina Muschetti observa una práctica semejante en su empleo general del lenguaje, señalando que ciertas palabras en la obra de Perlongher son "llevadas hasta el grado último en una ficción de mímesis, pulverizándola" (108). Su frase, una "ficción de mímesis," describe perfectamente lo que pasa en este cuento. Las perspectivas de los narradores que cuentan los episodios en primera persona son tan sospechosas como la "Evita" que conocen. Mientras la primera sección empieza contándonos cómo y cuándo la encontró por primera vez, la tercera empieza: "Si te digo dónde la vi la primera vez, te mentiría" (Prosa 194). El primer narrador muestra una falta de incredulidad al encontrar a la difunta en su sala llevando a cabo un acto sexual oral con su pareja, y cuando decide después que realmente es Evita, le ofrece un cointreau (recordando su gusto por bebidas finas). En los otros episodios Evita cuenta cómo es el cielo, se revela drogadicta y dama de beneficencia, y se involucra en una variedad de actividades sexuales con hombres identificados como maricas y también con otros. Termina la última sección con esta afirmación: "De esa esquina y del depto de los trolos los vagos nos borramos. Por eso los nombres que doy aquí son todos falsos" (Prosa 195). ¿Inclusive el nombre de Evita? El autor crea una imagen tan estrafalaria, tan extraordinaria, que llama la atención hacia su propio artificio, al hecho de que está manipulando un signo. Sin embargo, aun esta manipulación creó un escándalo; el autor les ofrece un desafío a sus lectores, el de no reaccionar a la promiscuidad de un ícono nacional llevado a extremos.

Perlongher emplea a Evita como un elemento en su proyecto más amplio de romper con la norma de todas formas. Presentando su obra prosaica, Ferrer y Baigorria caracterizan la trayectoria del deseo en su obra así: "El deseo no asumía una figura sólida, homo u heterosexual, sino que se impulsaba como fuerza que se hace estallar las clasificaciones con las cuales la normativa imperante, familiarista y capitalista, basaba su estrategia de control social" (Prosa 9). O, como dice el autor en uno de sus ensayos, "quiere hacer soltar todas las sexualidades" (Prosa 33), y romper tanto con el concepto de una sexualidad monolítica como con una política monolítica. Se necesita una imagen sagrada para hacerlo y Evita le ofrece ésta. Sin embargo, no destruye lo sagrado porque no funcionaría su burla, su desafío, 
sin poder contar con esta calidad elevada; se manipula la santidad de la imagen y la lleva hasta los márgenes para hacer resaltar su calidad construida. "Evita vive" es pura teatralidad, una representación anti-realista destinada para escandalizar.

Perlongher continúa combinando la poesía, la política y lo erótico en "El cadáver de la nación", una reescritura de Evita de 1989. Hay ecos de sus evocaciones anteriores a "la santa" en las imágenes y el lenguaje repetidos aquí (las uñas, su rodete), pero, a diferencia del cuento y el poema anterior, éste no tiene trama. "El cadáver de la nación" es totalmente imagen, pura superficie, el lenguaje plegándose sobre sí mismo como los pliegues del vestido de Evita al comienzo del poema. Se enfocan los elementos que, por lo común, se eliminan del discurso comunicativo, histórico, para ofrecernos un ejemplo concreto de la definición de Perlongher del Barroco: "El barroco consistiría básicamente en cierta operación de plegado de la materia y la forma" ("Introducción" 47-8). El lenguaje va y viene, doblándose sobre sí mismo, creando una textura visual y fónica, en vez de referirse a algún significado fuera de sí.

El yo poético está más distanciado en este poema, presente sólo en su manipulación de las partes del poema. Ahora no móvil sino fija, Evita está objetivizada: ella es "la santa", "la yaciente", "ella", "esa mujer", en la primera parte que se intitula "1. Zombi". Su nombre público aparece sólo una vez, más tarde, en la segunda sección — casi disociado de la persona, con minúscula y relacionado al verbo "evitar". Ella es un casco vacío, una superficie en la cual se puede tropar, o un espectáculo, la presencia material de su cuerpo embalsamado contradiciendo la chapa mítica. "Poder", la primera palabra del poema, se hace central por su deficiencia; "no da", "no alcanza", y "la potencia hedionda", se hace "la impotencia". Su autoridad política y social, duramente alcanzada, se ha transformado y ni la brujería ni la ciencia pueden revivificarla. Evita no puede ser "poseída" (ni por la ciencia moderna ni por el vudú alternativo), y nadie puede controlar su poder figurativo - lo que la hace el centro de este poema- porque este poder excede su cuerpo y su representación. ${ }^{13}$

La segunda sección abandona las estrofas en un movimiento decisivo hacia la prosa poética; hay un mínimo de puntuación, no hay versos como tal. Nuestra perspectiva vacila entre una visión de Evita flotando encima de la escena, luchando en contra del destino de su cuerpo y expresando sus sentimientos de traición e impotencia, y visiones de su cuerpo tratado por sus admiradores y por Pedro Ara, su embalsamador, retratado aquí como un bokor o sacerdote del vudú haitiano. No hay libertad en la muerte, ni escapatoria: "le deja al aire - libre no-" (73). La intervención científica que intenta "sustituir su sangre cancerosa por horchata de / orquídeas amazónicas," es artificial, inefícaz (73). Su cuerpo significa la intersección de la muerte y el deseo, esta vez en una versión asociada a la medicina. La conjunción de la muerte-el deseo-la medicina sugerida en el poema aparece explícitamente en lo que Perlongher ha escrito sobre el SIDA: "El SIDA introduce una forma clínica de la relación deseo-muerte" (El fantasma 97). Perlongher también hace esta observación acerca de la medicalización de la muerte y el deseo de la inmortalidad: "La medicina confisca y se apropia de la muerte, proveyendo respuestas tecnocráticas a miedos

${ }^{13}$ En su novela Santa Evita, Tomás Eloy Martínez observa que en esta segunda sección del poema Perlongher ha rearreglado pedazos de las notas del doctor español, Pedro Ara, sobre el proceso de embalsamar a Evita (163). Martínez también incluye especulaciones acerca de los orígenes de la resonancia de Evita entre los homosexuales argentinos (200-201). 
ancestrales y vendiendo sutilmente cierta ilusión de la inmortalidad" (El fantasma 84 ). La Evita muerta, en su presencia fantasmal, empieza a conjurar el espectro del SIDA. ${ }^{14}$

El estilo de prosa poética que suelta las fronteras genéricas continúa en la sección siguiente del poema que parece un fluir de la conciencia. Las palabras se ondulan como los rulos, doraditos, rodete, hebillas del cabello que se disuelven en las yemas aquí. Una voz poética, hablando desde la perspectiva de una primera persona, de modo directo y dominante rearregla el cuerpo de Evita - podría ser la voz del embalsamador, del peluquero, de la enfermera, o Evita misma vigilando su apariencia final. Su identidad se fusiona con la de sus guardianes en un lenguaje aliterado que une a todos estos hablantes posibles a través de su interés por su pelo, su apariencia, por la superficie que se deshace. El concepto de su fachada se extiende en la cuarta y última sección, en la que frases de su peluquero se esparcen con las de Evita; estos dos compiten con el embalsamador en la producción de su última imagen. Este fin sugiere una asociación entre estos "productores" y el poeta: como el peluquero, el poeta modela el estilo y como el embalsamador, perpetúa a Evita; todos ellos desnaturalizan la apariencia del sujeto (su objeto) a través del discurso, la imagen visual, el artificio, la nigromancia.

El deseo enlaza el miedo a la muerte en el primer poema a través de Evita; en el segundo caso, su cuerpo se hace una figura del deseo y la escritura homosexuales. Evita se conecta a la identidad homosexual masculina, entonces, de varias maneras. En un sentido, se la puede celebrar como una "mujer fálica", un personaje femenino poderoso adoptado por diversos grupos de argentinos como emblema de una femineidad activa. ${ }^{15} \mathrm{El}$ ascenso de clase y la transformación de Evita en la primera dama de la Argentina también llaman la atención hacia su construcción de sí misma, dándonos un ejemplo del concepto de Judith Butler del género sexual como una representación, una personificación excesiva, y una imitación para la cual no hay original (21). Diana Fuss ha hablado de la "espectralización de la identidad homosexual", señalando que "the first appearance of the homosexual as a 'species' rather than a 'temporary aberration' also marks the homosexual's disappearance [into the closet]" (4) [la primera aparición del homosexual como una 'especie' en vez de una 'aberración temporaria' también señala su desaparición (en el closet)]. Hay una analogía a Evita en esto porque ella gana su poder supremo y su inmortalidad en la muerte; muchas versiones de su vida comienzan con su fallecimiento cuando se hace figura, cuando se hace la incorporación del nacionalismo, materializándose más cuando desaparece. Su cuerpo embalsamado cobra una vida propia, como un cadáver animado; muerte en vida, ella ofrece una metáfora del fantasma del SIDA venidero.

En su poesía tardía, Perlongher, como sus antecendentes neobarrocos, Sarduy y Lezama, se detiene en el placer del texto, en los excesos del lenguaje. Perlongher describe este exceso como interrumpiendo la economía de los signos: "En el mercado del intercambio lingüístico, donde los significados son contabilizados en significantes legitimados

\footnotetext{
${ }^{14}$ Se podría hacer también un lazo directo a la homosexualidad. En su ensayo titulado "El sexo de las locas," Perlongher incluye esta frase: "Un fantasma corroe nuestras instituciones: la homosexualidad", una reescritura irónica del comienzo del Manifiesto comunista que reaparecerá en El fantasma del SIDA (Prosas 29).

15 Carol-Anne Tyler ha notado la predilección general del travesti por este estilo de femineidad en su artículo, "Boys Will be Girls: The Politics of Gay Drag".
} 
y fijos, se produce una alteración, una disputa: como si una feria gitana irrumpiese en el gris alboroto de la Bolsa" ("Introducción" 51). ${ }^{16}$ Esta técnica no borra el sentido, sino que lo oscurece por la profusión. Brad Epps, analizando el grotesco, otro signo de la inmoderación barroca, describe con perspicacia el lazo entre las prácticas simbólicas y las sexuales:

For is not the continuous movement in artifice and erotism; the sense of unproductive sensuality, strange subversion, and improper revolution; the putatively narcissistic focus on decay and death; the ornate form and degraded content of the grotesque; is not this already troped as homosexual? (50)

[el movimiento continuo en el artificio y el erotismo; el sentido de una sensualidad noproductiva, una subversión extraña, una revolución impropia; el foco supuestamente narcisista sobre la muerte y la decadencia; la forma ornamentada y el contenido degradado del grotesco; ¿no son interpretados ya como homosexual?]

El contenido homosexual subordinado en la poesía temprana de Perlongher se hace totalmente superficie en "El cadáver de la nación", y es una superficie múltiple, pluridimensional, no jerarquizada; la identidad homosexual se revela como un hilo de una tela compleja. Ambos poemas presentan una representación de la identidad sexual; en el primer caso, la puesta en escena revela sus propios silencios como elementos "que funcionan al lado de las cosas dichas" (Foucault 27). En el segundo caso, la visión que hace Perlongher de Evita depende de su naturaleza construida.

El concepto de un neo-barroco del cono sur (que Perlongher llamó "neo-barroso") inscribe la escritura de Perlongher en las tradiciones argentinas, caribeñas y españolas, haciéndola una puesta en escena formal de una identidad nacional que no se queda en lo argentino sino que cruza, se transnacionaliza. Perlongher mismo afirma que el Barroco se nomadiza desde el "náufrago peregrino" de las Soledades de Góngora que crea un parentesco entre "el nómade y el loco", un flujo que "parece apestar a perversión" (Prosas 116). Por lo tanto, es posible leer el neo-barroco aquí como otro tipo de travestismo que rompe las identidades nacionales mientras que las lleva a la vista, enfatizando las limitaciones de esta categoría, como cualquier otra. La práctica de llevar el exceso a la superficie que emplea Perlongher ejemplifica el artificio de la representación, la construcción de la imagen, del género sexual, y de la historia, ofreciéndonos, por lo tanto, otras inflexiones políticas posibles para el Barroco.

\section{BibLIOGRAFIA}

Baigorria, Osvaldo y Christian Ferrer. "Prólogo: Perlongher prosaico". Prosa plebeya: Ensayos 1980-1992. Buenos Aires: Ediciones Colihue, S.R.L., 1997. 7-12.

Boone, Bruce. "Gay Language as Political Praxis: The Poetry of Frank O'Hara". Social Text 1 (Winter, 1979): 59-92.

16 En un ensayo más temprano dice que: "No se afirma en vano que el barroco es el arte más escandalosamente antioccidental derivado del propio occidente", afirmando que este estilo es revolucionario por su excentricidad, su exceso en contra del racionalismo discursivo (Prosa 144). 
Butler, Judith. "Imitation and Gender Insubordination". Inside/Out: Lesbian Theories, Gay Theories. Diana Fuss, ed. Nueva York: Routledge, 1991. 13-31.

Cangi, Adrián y Paula Siganevich. Lúmpenes peregrinaciones: Ensayos sobre Néstor Perlongher. Rosario: Beatriz Viterbo Editora, 1996.

Edelman, Lee. Homographesis: Essays in Gay Literary and Cultural Theory. Nueva York: Routledge, 1994.

"Tearooms and Sympathy, or, the Epistemology of the Water Closet". The Lesbian and Gay Studies Reader. Henry Ablelove, Michele Aina Barale, David M. Halperin, eds. Nueva York: Routledge, 1993. 553-574.

Epps, Brad. "Grotesque Identities: Writing, Death, and the Space of the Subject". The Journal of the Midwest Modern Language Association 28/1 (Spring, 1995): 38-55.

Ferrer, Christian. "Escamas de un ensayista". Lúmpenes peregrinaciones: Ensayos sobre Néstor Perlongher. Rosario: Beatriz Viterbo Editora, 1996. 181-193.

Foucault, Michel. The History of Sexuality: Volume 1: An Introduction. Robert Hurley, trad. Nueva York: Vintage Books, 1990.

Fuss, Diana. "Inside/Out". Inside/Out: Lesbian Theories, Gay Theories. Diana Fuss, ed. Nueva York: Routledge, 1991. 1-12.

González, Horacio. "Introito: Perlongher y la crítica argentina". Lúmpenes peregrinaciones: Ensayos sobre Néstor Perlongher. Rosario: Beatriz Viterbo Editora, 1996. 9-16.

Johnson, Barbara. The Critical Difference: Essays in the Contemporary Rhetoric of Reading. Baltimore: Johns Hopkins Press, 1980.

Martínez, Tomás Eloy. Santa Evita. Buenos Aires: Editorial Plantea, 1995.

Murray, Stephen O. y Manuel Arboleda G. "Stigma Transformation and Relexification: Gay in Latin America". Latin American Male Homosexualities. Stephen O. Murray, ed. Albuquerque: University of New Mexico Press, 1995. 138-144.

Muschetti, Delfina. "Píntenos el alma, Padre". Lúmpenes peregrinaciones: Ensayos sobre Néstor Perlongher. Rosario: Beatriz Viterbo Editora, 1996. 105-114.

Panesi, Jorge. "Detritus”. Lúmpenes peregrinaciones: Ensayos sobre Néstor Perlongher. Rosario: Beatriz Viterbo Editora, 1996. 44-61.

Perlongher, Néstor. Prosa plebeya: Ensayos 1980-1992. Buenos Aires: Ediciones Colihue, S.R.L., 1997.

Lamê: Antologia bilingüe espanhol-português. São Paulo: Editora da UNICAMP, 1994.

El chorreo de las iluminaciones. Caracas: Pequeña Venecia, 1992.

Aguas Aéreas. Buenos Aires: Último Reino, 1991.

Parque Lezama. Buenos Aires: Sudamericana, 1990.

Hule. Buenos Aires: Ediciones Último Reino, 1989.

El fantasma del SIDA. Osvaldo Pedrozo, trad. Buenos Aires: Punto Sur Editores, 1988.

Alambres. Buenos Aires: Ediciones Último Reino, 1987.

Austria-Hungría. Buenos Aires: Tierra Baldía, 1980.

"Introducción a la poesía neobarroca cubana y rioplatense". Revista chilena de literatura 41 (1992): 47-57. 
Tyler, Carole-Anne. "Boys Will Be Girls: The Politics of Gay Drag". Inside/Out: Lesbian Theories, Gay Theories. Diana Fuss, ed. Nueva York: Routledge, 1991. 32-70.

Zapata, Miguel Ángel. "Néstor Perlongher: La parodia diluyente". Inti 24-25 (1987-88): 285-297. 